\title{
Residual fuel atomization process simulation
}

The process of atomization of fuel in engines with compression ignition is determining in organization of the combustion process, the result of which are the economic and environmental performance of the engine. One of the main parameters of the spray jet fuel is the mean droplet diameter. The article presents the results of analytical and experimental studies by the definition of mean diameter of Sauter droplet of atomized residual fuel IFO380.

Key words: diesel engines, residual fuel, mean diameter of Sauter

\section{Introduction}

The decision to reduce the emission of toxic components in the exhaust gases of internal combustion engines can be considered in three stages depending on each other: the introduction of carbohydrate fuels into the combustion chamber, their burning out with the formation of incomplete combustion products, nitrogen and sulfur oxides, as well as their reduction and oxidation in the exhaust system. The main stage is the combustion process, which is determined by the fuel supply characteristic and the design parameters of the combustion chamber and the intake path. When the organization of a low-toxicity work process depends on the spraying of hydrocarbon fuels. Especially it concerns for heavy fuel grades used in low-speed marine diesel engines, the physical parameters of which are different from distilled fuels used in medium- and high-speed diesel engines. In the literature of the subject of research there are no results of scientific and experimental design work in this direction, so modeling the process of spraying heavy fuel is a very urgent task.

\section{Fuel atomization in the diesel engines}

As is known, the combustion of hydrocarbon fuel in compression-ignition engines is preceded by physical and chemical processes that can be represented in the following sequence: a volume of fuel is injected, jet break up into droplets, fuel droplets evaporate, fuel vapor mixes with hot air in cylinder, fuel molecules forms free radicals, ignition and combustion. It should be noted that each element in the presented sequence is determined by the specific physical parameters of the fuel: jet break up into droplets depend from fuel viscosity and surface tension; fuel droplets evaporate - from fuel specific heat; vapor pressure, heat of vaporization, and fuel vapor mixes with hot air in cylinder - from fuel vapor diffusivity $[12,15]$.

The main criterion for the quality of the atomized fuel is the droplet diameter. By spraying, the surface of the cyclic portion increases, thereby increasing the amount of perceived heat and the rate of evaporation of the droplets. When the diameter of the droplet determines the macrostructure (the opening angle and the range) and the microstructure (size and distribution of droplets) of the jet. In practice, a theoretical jet consisting of droplets of the same size is used to determine the quality of spraying and which has characteristics similar to the actual jet, for example the total number of drops, the sum of their surface, volume or diameter $[5,6]$.

For the conditions of heat exchange, evaporation and combustion of a drop corresponding to the conditions of the combustion chamber of diesel engines, the average diameter of the Sauter $\left(D_{32}\right.$ or SMD) is taken as the criterion for the quality of spraying, expressing the ratio of the volume to the surface of the drop in the theoretical jet $[3,15]$ :

$$
\mathrm{SMD}=\frac{\sum \mathrm{N}_{\mathrm{i}} \mathrm{D}_{\mathrm{i}}^{3}}{\sum \mathrm{N}_{\mathrm{i}} \mathrm{D}_{\mathrm{i}}^{2}}
$$

In the literature of the subject of research, it is possible to find the equations determining the average droplet diameter according to Sauter (Table 1).

Table 1. Calculation formulas for determining the mean diameter of a drop

\begin{tabular}{|c|c|c|}
\hline Equation & & Author \\
\hline $\begin{array}{l}\mathrm{SMD}=3330 \mathrm{~d}_{0}^{0.3} \mu_{\mathrm{L}}^{0.07} \rho_{\mathrm{L}}^{-0.648} \times \\
\times \sigma^{-0.15} \mathrm{U}_{\mathrm{L}}^{-0.55} \mu_{\mathrm{G}}^{0.78} \rho_{\mathrm{G}}^{-0.052}\end{array}$ & (2) & $\begin{array}{l}\text { Harmon } \\
{[1,2]}\end{array}$ \\
\hline $\mathrm{SMD}=\frac{47 \mathrm{~d}_{0} \sigma^{0,25}(1+3310 \mathrm{~h})}{\mathrm{U}_{\mathrm{L}} \rho_{\mathrm{G}}^{0.25}}$ & (3) & $\begin{array}{l}\text { Tanasawa and } \\
\text { Toyoda } \\
{[1,5]}\end{array}$ \\
\hline $\begin{array}{l}\mathrm{SMD}=3.08 v_{\mathrm{L}}^{0.385}\left(\sigma \rho_{\mathrm{L}}\right)^{0.737} \times \\
\times \rho_{\mathrm{G}}^{0.06} \Delta \mathrm{P}_{\mathrm{L}}^{-0.54}\end{array}$ & (4) & $\begin{array}{l}\text { Elkotb } \\
{[1,4]}\end{array}$ \\
\hline $\begin{array}{l}\mathrm{SMD}=0.38 \mathrm{~d}_{0} \operatorname{Re}^{0.25} \mathrm{We}^{-0.32} \times \\
\times\left(\frac{\mu_{\mathrm{L}}}{\mu_{\mathrm{G}}}\right)^{0.37}\left(\frac{\rho_{\mathrm{L}}}{\rho_{\mathrm{G}}}\right)^{-0.47}\end{array}$ & (5) & $\begin{array}{l}\text { Hiroyasu and } \\
\text { Arai } \\
{[1,7]}\end{array}$ \\
\hline $\mathrm{SMD}=2330 \rho_{\mathrm{G}}^{0.121} \mathrm{Q}_{\mathrm{L}}^{0.131} \Delta \mathrm{P}_{\mathrm{L}}^{-0.135}$ & (6) & $\begin{array}{l}\text { Hiroyasu and } \\
\text { Kadota }[1,7]\end{array}$ \\
\hline $\mathrm{SMD}=0.53 \frac{\mathrm{Q}_{\mathrm{L}}^{0.27} \mathrm{~d}_{0}^{0.27} \mu_{\mathrm{L}}^{0.69} \rho_{\mathrm{G}}^{0.48} \mathrm{C}_{0}^{0.97}}{\rho_{\mathrm{L}}^{-0.21} \Delta \mathrm{P}_{\mathrm{L}}^{-0.21}}$ & (7) & $\begin{array}{l}\text { Hansmann } \\
{[1]}\end{array}$ \\
\hline $\mathrm{SMD}=0.158\left(\frac{\sigma}{\rho_{\mathrm{L}}}\right)^{0.354} \mu_{\mathrm{L}}^{0.303} \mathrm{Q}_{\mathrm{L}}^{0.139}$ & (8) & $\begin{array}{l}\text { Mochida } \\
{[1]}\end{array}$ \\
\hline $\mathrm{SMD}=\frac{10^{6} \mathrm{E}_{32} \mathrm{~d}_{0} \mathrm{M}^{0.0733}}{(\rho \mathrm{We})^{0.266}}$ & (9) & $\begin{array}{l}\text { Kuleshov } \\
{[14]}\end{array}$ \\
\hline
\end{tabular}

Listed in the Table 1 equations, show a different approach of the authors to a mathematical description of the fuel atomization process. So, for example, in the equations there is a significant difference in the magnitude of the constant coefficients and the exponents for the same physical parameters - by equation 2 , an increase in the surface tension leads to an increase in the SMD, according to equa- 
tions 4 and 6 , higher counterpressure values contribute to better sputtering, according to equation 7 - this relationship has the opposite meaning. Equations 6 and 7 do not take into account the effect of surface tension on SMD, although at spraying the fragmentation of droplets continues until the surface tension forces become larger than the total forces causing the jet to decay.

Constant coefficients and exponents in the above equations, taking into account the effect of various physical fuel parameters on the average droplet diameter, were obtained experimentally by various methods and means of measurement and indicate the depth of the processes that require further research. Especially this applies to heavy grades of fuel used in marine diesel engines and differing in physical parameters from light grades.

\section{Experimental installation}

Determination of the quality of the sprayed fuel was carried out on an experimental test bench consisting of three main elements (Fig. 1): Nozzle attachment unit, with the ability to move it vertically and horizontally, the Spraytec STP 5000 apparatus from Malvern Instruments and the EPS 200 installations from Bosch and PRW-3 fuel injector adjustment.

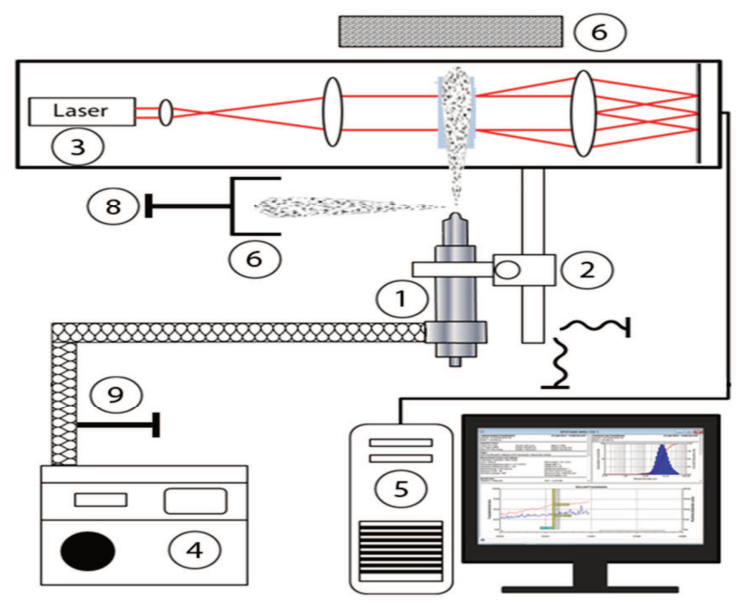

Fig. 1. Scheme of the experimental device for determining the quality of the atomized fuel: 1 - nozzle, 2 - nozzle attachment point, 3 - Spraytec STP 5000 device, 4 - EPS 200 installation, 5 - personal computer, 6 spray catchers, 7 - fume hood, 8,9 - thermocouples

The nozzle attachment unit was equipped with micrometric screws to control the position of a single fuel jet directed to the measurement zone, as well as traps of the remaining jets of sprayed fuel. Thus, it was possible to measure the parameters of the sprayed fuel only from one nozzle opening, and the remaining fuel jets did not affect the accuracy of the results obtained (Fig. 2).

To determine the distribution of the droplet size in a jet of sprayed fuel, an apparatus of the Spraytec STP 5000 type was used whose operation is based on the measurement of the scattering of the He-Ne laser beam (Fig. 3). The system consists of 30 detectors which detects light scattering on the drops and converts it into an electrical signal. The angle at which the drop disperses the light is inversely proportional to its diameter - while smaller droplets correspond to a larger angle. Each detector senses a light signal in a certain range of scattering angles. At present, the method of laser diffraction is the most accurate method for determining the droplet size in aerosols and liquids, which makes it possible to use it to determine the quality of spraying of diesel fuel.

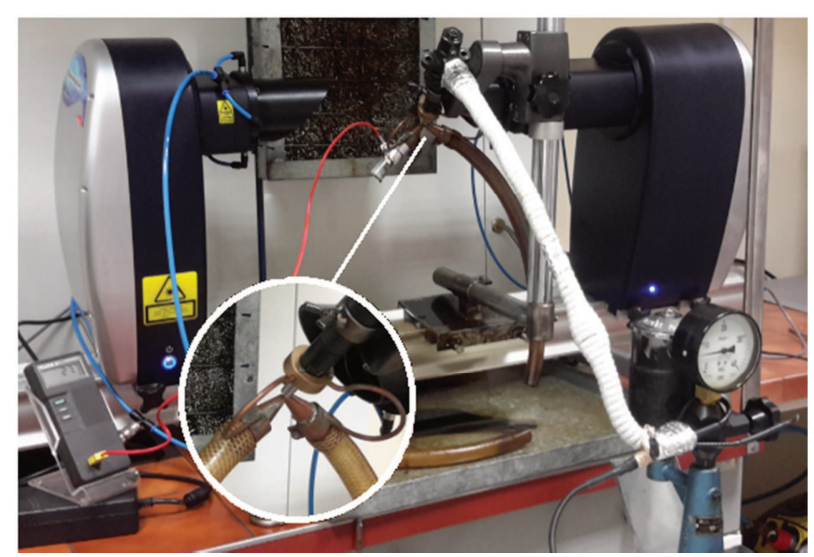

Fig. 2. Experimental installation with traps of separate jets of sprayed fuel
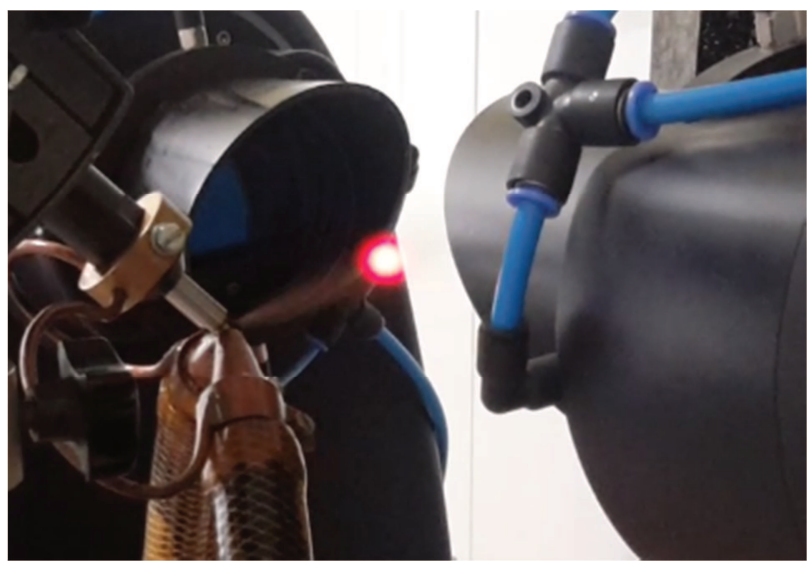

Fig. 3. Scattering beam light on fuel droplets

The main technical characteristics of the device Spraytec STP 5000 firm Malvern Instruments are listed in the Table 2 [9].

Table 2. Basic technical data of the Spraytec STP 5000

\begin{tabular}{|l|l|}
\hline Method of measurement & $\begin{array}{l}\text { Laser-diffraction (small-angle scatte- } \\
\text { ring) }\end{array}$ \\
\hline Range of measured drops & $0.1-900 \mu \mathrm{m}, \mathrm{Dx}(50): 0.5-600 \mu \mathrm{m}$ \\
\hline Optical model & $\begin{array}{l}\text { The Mie theory and the Fraunhofer } \\
\text { approximation }\end{array}$ \\
\hline Aerosol concentration range & $\begin{array}{l}\text { Multiple Dispersion Correction } \\
\text { System }\end{array}$ \\
\hline Light source & Laser type He-Ne, $2 \mathrm{~mW}, 632.8 \mathrm{~nm}$ \\
\hline Measurement error & Does not exceed $\pm 1 \%$ for Dx $(50)$ \\
\hline
\end{tabular}

\section{Results and Discussions}

An important point in preparing fuel for combustion is to provide the necessary viscosity. If for diesel fuels the need for heating to reduce the viscosity is eliminated, then for heavy fuels, preheating in steam or electric heaters is a prerequisite for their preparation, since only this way it is possible to achieve the required viscosity. The effect of viscosity and compressibility on the injection characteristic, depending on the design of the fuel equipment, is different, but in all cases it affects to some extent the quality of 
spraying and subsequent combustion of fuel. The viscosity, determined by the forces of the internal cohesion of the fuel, and the forces of its surface tension, have a direct effect on the decay of the jet of fuel flowing from the nozzle $[10,11,13]$. Before the test, heavy fuel was heated, during the experiment it gradually cooled down (Fig. 4). The temperature in the tank and the fuel trap was constantly measured by thermocouples of the Fluke 52II type.

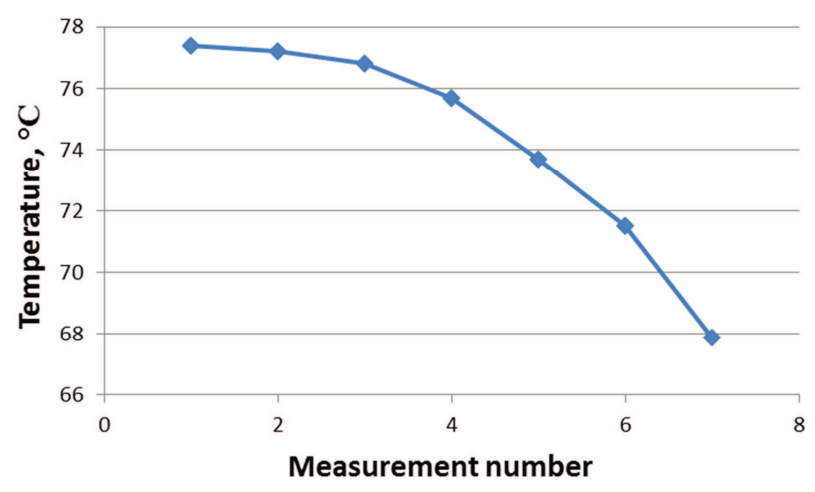

Fig. 4. Change in fuel temperature during the experiment.

The parameters of the test fuel that directly affect the average droplet diameter, such as density, viscosity and surface tension, as well as the characteristics of the injector and the injection conditions are shown in Table 3.

Table 3. Characteristics of the injector, fuel, environment.

\begin{tabular}{|l|c|r|}
\hline Parameter & Unit & Value \\
\hline Nozzle & Tipe & D1LMK 148/1 \\
\hline Nozzle hole diameter & $\mathrm{mm}$ & 0.34 \\
\hline Axial length of nozzle & $\mathrm{mm}$ & 1.2 \\
\hline Pressure difference & $\mathrm{MPa}$ & 20 \\
\hline Air density, $20^{\circ} \mathrm{C}$ & $\mathrm{kg} / \mathrm{m}^{3}$ & 1.16 \\
\hline Fuel density, $15^{\circ} \mathrm{C}$ & $\mathrm{kg} / \mathrm{m}^{3}$ & 986 \\
\hline Fuel kinematic viscosity, $50{ }^{\circ} \mathrm{C}$ & $\mathrm{cSt}$ & 380 \\
\hline Fuel surface tension, $20^{\circ} \mathrm{C}$ & $\mathrm{N} / \mathrm{m}$ & 0.0369 \\
\hline
\end{tabular}

Surface tension is an unregulated in the standards physical parameter of fuel, which affects the fineness of the spraying, thereby the combustion efficiency and the environmental performance of the engine. The smaller the surface tension of the fuel, the lower the resistance is to the forces that cause the jet to decay. During the experiment, the temperature of the fuel was constantly changing, along with its physical parameters. The change in surface tension from temperature is shown in Fig. 5.

As described above, many mathematical models of calculating SMD have been proposed in the literature. Figure 6 shows the curves for calculating the SMD from the temperature for fuel IFO-380 according to the equations of different authors and data on the Spraytec experiment. As can be seen from the figure, the calculation results range from 10 to $80 \mu \mathrm{m}$. In the temperature range from 68 to 72 , the result is closer to the experiment by the Hansmana equation, but from $74^{\circ} \mathrm{C}$ the curves diverge, which means that the SMD dependences on temperature are different. SMD by Hiroyasu and Katoda as the temperature decreases, though slightly, but reduced, which contradicts the theory and other calculations. It should also be noted that the Hiroyasu and
Katoda equation does not take into account such a parameter as the surface tension of the fuel. The results for the Elkotb and Mochida equations are close to each other, but they are very far from the results of the experiment. The equation of Tanasawa and Toyoda displays an almost parallel curve to the results of the experiment. According to the Kuleshov equation, the SMD coincides at a temperature of $68^{\circ} \mathrm{C}$.

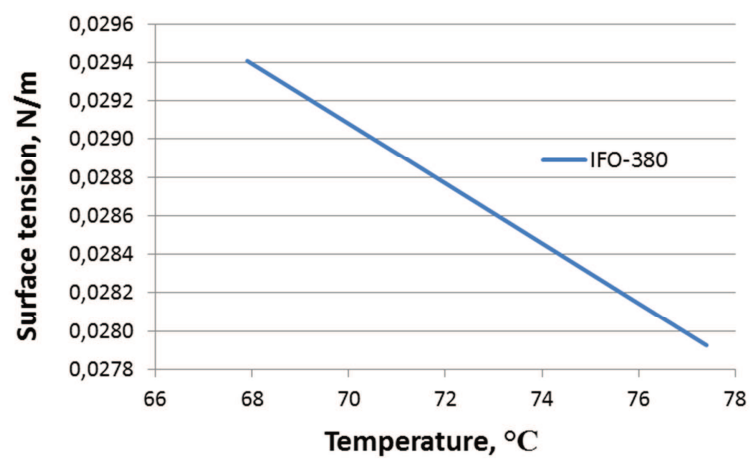

Fig. 5. Dependence of surface tension of fuel IFO-380 on temperature

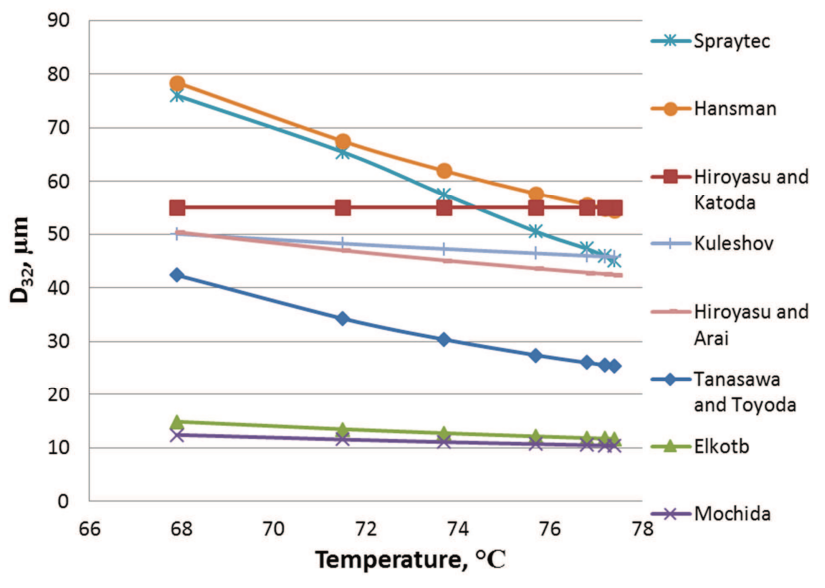

Fig. 6. Calculation of the SMD for mathematical models and the result of the experiment at different temperatures

Since there is an empirical coefficient in the Kuleshov equations, the value of which depends on the experimental conditions, we assume that it has a temperature dependence (Fig. 7).

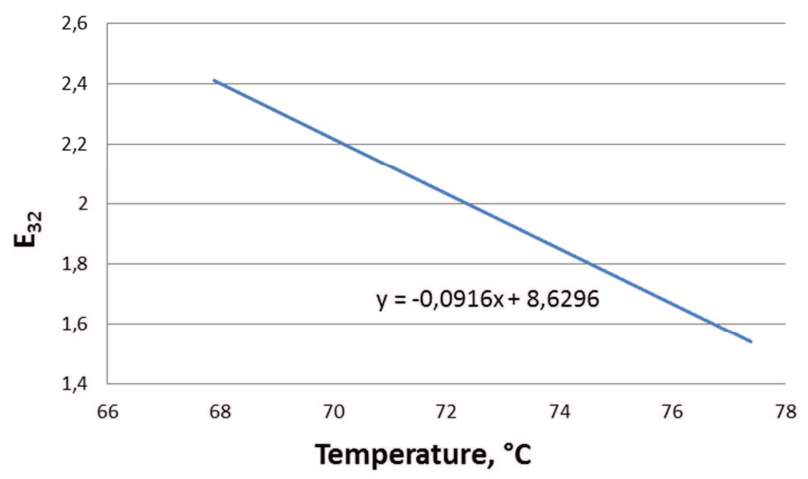

Fig. 7. The change in $\mathrm{E}_{32}$ from temperature 
Calculation by the Kuleshov equation with a varying coefficient $\mathrm{E}_{32}$ shows good agreement with the result of the experiment. Also, when the coefficient of 1.83 is added to the Tanasawa and Toyoda equation, the calculation result is close to the experimental (Fig. 8).

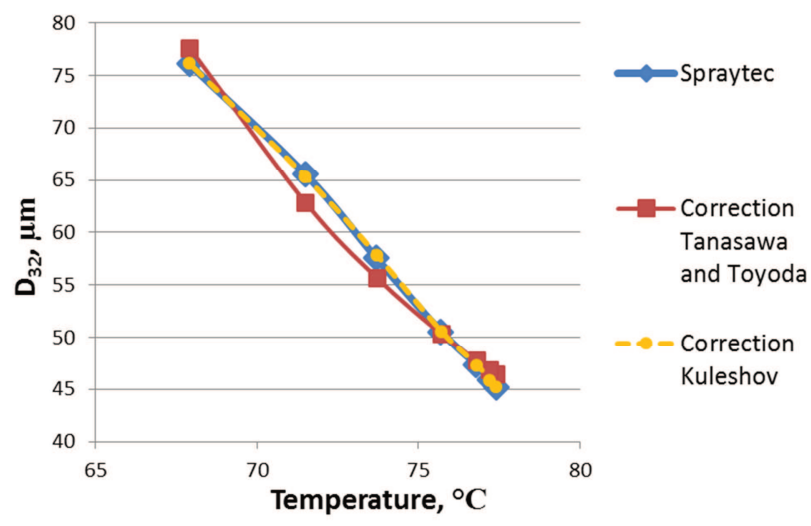

Fig. 8. SMD on experiment and on corrected mathematical models

Thus, for heavy fuel grades, we can recommend the determination of the mean Sauter diameter by the Kuleshov equation with the introduction of the correction $E_{32}\left(f_{T}\right)$, taking into account the temperature dependence:

$$
\mathrm{SMD}=\frac{10^{6} \mathrm{E}_{32}\left(\mathrm{f}_{\mathrm{T}}\right) \mathrm{d}_{0} \mathrm{M}^{0.0733}}{(\rho \mathrm{We})^{0.266}}
$$

At the same time, in the Tanasawa and Toyoda equations, a correction factor of 1.83 should be used. The use of these corrections leads to an approximation of the analytical dependences to the experimental data with a correlation coefficient of 0.99 .

\section{Conclusions}

The process of fuel atomization is one of the most important stages in the complex of physical and chemical processes preceding the combustion and heat generation in the combustion chamber of compression-ignition engines. It is this stage that affects the magnitude of the ignition delay, the degree of buildup of pressure and temperature in the cylinder, thereby determining the economic and environmental parameters of the engine. The quality of fuel atomization is conveniently represented by the average diameter of droplet in the jet (SMD), and although this parameter is conditional, nevertheless its quantitative characteristic can be used in modeling the fuel delivery process in diesel engines. In recent years, instead of a full experimental study, modeling is becoming an attractive alternative for analyzing engine performance. This is especially true for heavy fuel grades, for which the results of calculations should be sufficiently detailed for the purpose of their subsequent comparison with experimental data and data from other calculation methods.

The equations of SMD calculation presented in the paper, which were encountered in the literature, were obtained for a specific type of liquid with certain physical parameters, but not all are suitable for heavy types of fuel. When choosing a mathematical model for heavy fuel, the Tanasawa and Toyoda and Kuleshov equations were chosen, since the results for the Tanasawa and Toyoda equation lie on the graph almost parallel to the experimental results, and in the Kuleshov equation there is a separate empirical coefficient, the value of which can be selected for heavy fuel. The corrected Tanasawa and Toyoda equation by a factor of 1.83 and calculation by the Kuleshov equation with a variable coefficient $\mathrm{E}_{32}\left(\mathrm{f}_{\mathrm{T}}\right)$ showed good agreement with the results of the experiment.

\section{Nomenclature}

SMD Sauter mean diameter, $\mu \mathrm{m}$

Oh Ohnesorge number

Re Reynolds number

We Weber number

$\mathrm{C}_{0} \quad$ discharge coefficient of the nozzle

$\mathrm{N}_{\mathrm{i}}$ number of drops with a given outer diameter

$\mathrm{D}_{\mathrm{i}} \quad$ diameter of droplets of a given size, $\mu \mathrm{m}$

$\mathrm{d}_{0} \quad$ initial jet diameter, $\mathrm{m}$

$\mu_{\mathrm{L}} \quad$ liquid dynamic viscosity, $\mathrm{Pa} \cdot \mathrm{s}$

$\rho_{\mathrm{L}} \quad$ liquid density, $\mathrm{kg} / \mathrm{m}^{3}$

$\sigma \quad$ surface tension, $\mathrm{N} / \mathrm{m}$
$v_{\mathrm{L}} \quad$ liquid kinematic viscosity, $\mathrm{m}^{2} / \mathrm{s}$

$\mathrm{U}_{\mathrm{L}} \quad$ liquid velocity, $\mathrm{m} / \mathrm{s}$

$\Delta \mathrm{P}_{\mathrm{L}} \quad$ pressure differential across nozzle, $\mathrm{Pa}$

$\mathrm{Q}_{\mathrm{L}} \quad$ mass flow rate, $\mathrm{kg} / \mathrm{s}$

$\mu_{\mathrm{G}} \quad$ gas dynamic viscosity, $\mathrm{Pa} \cdot \mathrm{s}$

$\rho_{\mathrm{G}} \quad$ gas density, $\mathrm{kg} / \mathrm{m}^{3}$

$\rho \quad \rho_{\mathrm{G}} / \rho_{\mathrm{L}}$

M $\quad \mu_{\mathrm{L}}^{2} /\left(\mathrm{d}_{0} \rho_{\mathrm{L}} \sigma\right)$

$\mathrm{E}_{32}$ empirical coefficient

$\mathrm{E}_{32}\left(\mathrm{f}_{\mathrm{T}}\right)$ temperature dependence empirical coefficient

\section{Bibliography}

[1] ASHGRIZ, H. Handbook of atomization and sprays. Theory and applications. Springer. 2011.

[2] CAI, H., SONG, B., PEI, Y., SHI. S. Fuel leaking analysis of fuel tank by projectiles impact with mechanical properties of projectiles. Advanced materials research. 2013, 644, 203206.

[3] FILIPPA, L., TRENTO, A., ÁLVAREZ, A.M. Sauter mean diameter determination for the fine fraction of suspended sediments using a LISST-25X diffractometer. Measurement. 2012, 45(3), 364-3687.

[4] KENNETH, W.R., KENNETH, M.B. Combustion engineering, Second edition. CRC Press Taylor and Francis. 2011.

[5] LEFEBVRE, A.H. Atomization and sprays. Hemisphere Publishing Corporation. New York. 1989.

[6] LIU, H. Science and engineering of droplets - fundamentals and applications. William Andrew Publishing, New York, USA. 2000.

[7] SANTOS, F.D., MOYNE, L.L. Spray atomization models in engine applications, from correlations to direct numerical 
simulations. Oil \& Gas Science and Technology - Rev. IFP Energies nouvelles. 2011, 66(5), 801-822.

[9] Spraytec user manual. Malvern Instruments Ltd. MAN0368 issue 3.0. 2007.

[10] TOTTEN, E.G., WESTBROOK, R.S., SHAH, J.R. Fuels and lubricants handbook: technology, properties, performance and testing. ASTM manual series: MNL37WCD, USA. 2003, 1087.

[11] QING, S., JIXIAN, G., YUHUI, L. et al. Estimation of the sauter mean diameter for biodiesels by the mixture topological index. Renewable energy. 2011, 36(2), 482-487.

[12] ZABŁOCKI M. Wtrysk i spalanie paliwa w silnikach wysokoprężnych. WKit, Warszawa. 1976.

Prof. Oleh Klyus, DSc., DEng., D.h.c. - Maritime University of Szczecin.

e-mail: olegklus@o2.pl
[13] ЗАРЕЦКАЯ, А.К. Технология использования топлива, масла и воды. Конспект лекиий, Керчь. 2014.

[14] КУЛЕШОВ, А.С. Программа расчета и оптимизации двигателей внутреннего сгорания ДИЗЕЛЬ-РК. Описание математических моделей, решение оптимизационных задач. МГТУим. Н.Э.Баумана. 2004.

[15] РАЗЛЕЙЦЕВ, Н.Ф. Моделирование и оптимизация процесса сгорания в дизелях. Вища школа: Изд-во при Харьк. ун-те. 1980.

Nadezhda Zamiatina - Faculty of Marine Technology and Natural Sciences at Klaipeda University.

e-mail: Nadezda.Zamiatina@ku.lt

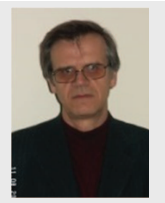

